\title{
SIMULASI ETAP 12.6 PADA REKONFIGURASI JARINGAN DISTRIBUSI KOTA PAYAKUMBUH
}

\author{
Muhammad Qori Shipa ${ }^{1}$, Albert Gifson ${ }^{2}$ \\ 1,2, Institut Teknologi PLN \\ Jl. Lingkar Luar Barat Duri Kosambi Cengkareng Jakarta Barat \\ 1orishipa@gmail.com, ${ }^{2}$ albert.gifson@itpln.ac.id
}

\begin{abstract}
ABSTRAK
Rekonfigurasi jaringan berupa penarikan jaringan dari feeder 2 Situjuah ke feeder 3 Aur Kuning dilakukan untuk mengurangi susut daya dan untuk menciptakan saluran baru untuk proses manuver guna menjaga PLTA Batang Agam tetap terhubung dengan Gardu Induk $150 \mathrm{kV}$ untuk sistem Interkoneksi.. Pada penelitian ini dilakukan analisis data konfigurasi jaringan sehingga dapat membuktikan penarikan jaringan SUTM dari feeder 2 Situjuah ke feeder 3 Aur Kuning merupakan lokasi yang tepat. Penarikan jaringan SUTM akan disimulasikan menggunakan software electrical transient analyzer program (ETAP) versi 12.6 untuk mengamati proses manuver dan mengamati penurunan nilai susut daya. Hasil penelitian berupa skema agar dapat lebih mudah dipahami, dan disimulasikan untuk memperoleh data susut daya yang akan dibandingkan nilai susut daya jaringan distribusi sebelum dan sesudah rekonfigurasi sebagai tolak ukur perubahan keandalan sistem. Nilai susut daya sebelum rekonfigurasi jaringan ialah sebesar 0,499 MW. Setelah dilakukan rekonfigurasi jaringan nilai susut daya menurun, dengan menggunakan penghantar $240 \mathrm{~mm}^{2}$ nilai susut daya terkecil diperoleh sebesar 0,319 MW. Kemudian dengan penghantar $150 \mathrm{~mm}^{2}$ nilai susut daya sebesar 0,324 MW. Dan dengan penghantar $70 \mathrm{~mm}^{2}$ nilai susut daya sebesar 0,340 MW.
\end{abstract}

Kata Kunci: Rekonfigurasi, Manuver, Interkoneksi, Penarikan Jaringan

\begin{abstract}
Network reconfiguration in the form of network withdrawal from feeder 2 Situjuah to feeder 3 Aur Kuning was carried out to reduce power losses and to create new channels for the maneuvering process to keep the Batang Agam hydropower plant connected to the $150 \mathrm{kV}$ substation for the Interconnection system. In this study, data analysis was carried out. network configuration so that it can prove the SUTM network withdrawal from feeder 2 Situjuah to feeder 3 Aur Kuning is the right location. The towing of the SUTM network will be simulated using the electrical transient analyzer program (ETAP) software version 12.6 to observe the maneuvering process and observe a decrease in the value of power losses. The results of the study are in the form of a schema so that it can be more easily understood and simulated to obtain power loss data that will be compared to the power loss value of the distribution network before and after reconfiguration as a benchmark for changes in system reliability. The value of power loss before network reconfiguration is $0.499 \mathrm{MW}$. After reconfiguring the network, the value of power loss decreases, using a $240 \mathrm{~mm} 2$ conductor the smallest power loss value is obtained at $0.319 \mathrm{MW}$. Then with a $150 \mathrm{~mm} 2$ conductor, the power loss value is $0.324 \mathrm{MW}$. And with a 70 mm2 conductor, the power loss value is $0.340 \mathrm{MW}$.
\end{abstract}

Key Word: Reconfiguration, Maneuvering, Interconnection, Network Pulling

\section{PENDAHULUAN}

Semakin hari kebutuhan manusia dengan energi listrik semakin besar, hal ini dikarenakan modernisasi yang dimana segala aktivitas manusia tidak dapat terlepas dari penggunaan energi listrik. Energi listrik yang biasa digunakan sehari-hari berasal dari listrik yang disalurkan dari pembangkit-pembangkit listrik melalui sistem interkoneksi.

Energi listrik pada jaringan distribusi Kota Payakumbuh disuplai oleh PLTA Batang Agam dengan kapasitas $3 \times 3.5$ MW serta sistem interkoneksi yang terhubung melalui Gardu Induk Payakumbuh. PLTA Batang Agam mempunyai 4 feeder keluaran yang langsung terhubung dengan jaringan distribusi $20 \mathrm{kV}$ yaitu feeder 1 Bukittinggi, feeder 2 Situjuah, feeder 3 Payakumbuh 1 dan feeder 4 Batu Hampar. Diantara keempat feeder tersebut, feeder 3 Payakumbuh 1 dan feeder 1 Bukittinggi merupakan penyulang yang menghubungkan PLTA Batang Agam dengan sistem interkoneksi melalui Gardu Induk Payakumbuh dan Gardu Induk Bukittingi. Akan tetapi penghantar antara feeder 1 Bukittinggi dengan PLTA Batang Agam mengalami gangguan yang cukup sering akibat kondisi geografis yang tidak menguntungkan sehingga karena alasan keekonomisan feeder 1 
Bukittinggi tidak lagi dihubungkan dengan PLTA Batang Agam.

Konfigurasi jaringan distribusi Kota Payakumbuh saat ini dinilai kurang handal diakibatkan hanya ada satu feeder yang menghubungkan PLTA Batang Agam dengan sistem interkoneksi, hal ini juga dapat mempengaruhi besarnya nilai susut daya pada jaringan distribusi Kota Payakumbuh. Nilai susut daya pada jaringan menggambarkan besar kerugian bagi PT.PLN (Persero) selaku perusahaan yang bertugas dalam menghasilkan energi listrik untuk disalurkan kepada konsumen. Untuk itu perlu diadakan rekonfigurasi jaringan pada jaringan distribusi Kota Payakumbuh guna menurunkan nilai susut daya sehingga dapat menjaga kontinuitas penyaluran dan kenadalan jaringan distribusi Kota Payakumbuh.

Pada penelitian ini, akan dilakukan studi perencanaan rekonfigurasi jaringan distribusi dengan penarikan jaringan SUTM dengan menghubungkan feeder 2 situjuh dengan feeder 3 aur kuning dalam mengurangi susut daya untuk meningkatkan keandalan jaringan distribusi Kota Payakumbuh. Permodelan rekonfigurasi jaringan akan disimulasikan menggunakan software Electrical Transient Analyzer Program (ETAP) versi 12.6 untuk mengamati proses manuver dan memperoleh data dari nilai susut daya sebelum dan sesudah rekonfigurasi jaringan.

\section{METODE PENELITIAN}

Metode penelitian ini adalah membandingkan nilai susut daya pada jaringan distribusi Kota Payakumbuh sebelum rekonfigurasi jaringan dan sesudah rekonfigurasi jaringan dengan beberapa jenis luas penampang penghantar yang akan digunakan. Berikut adalah single line diagram sebelum dan sesudah rekonfigurasi jaringan distribusi Kota Payakumbuh :

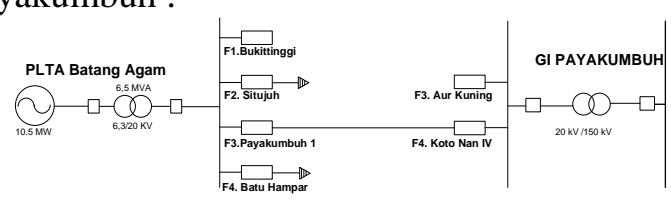

Gambar 1 Single Line Diagram

Metode penelitian yang dilakukan yaitu dengan menggunakan simulasi Electrical Transient Analysis Program (ETAP) versi 12.6. ETAP merupakan suatu perangkat lunak yang mendukung sistem tenaga listrik. Perangkat ini mampu bekerja dala keadaan offline untuk simulasi tenaga listrik, serta online untuk pengelolaan data secara realtime. Fitur yang terdapat didalamnya bermacam-macam antara lain fitur yang digunakan untuk menganalisa pembangkitan tenaga listrik, sistem transmisi maupun sistem distribusi tenaga listrik.

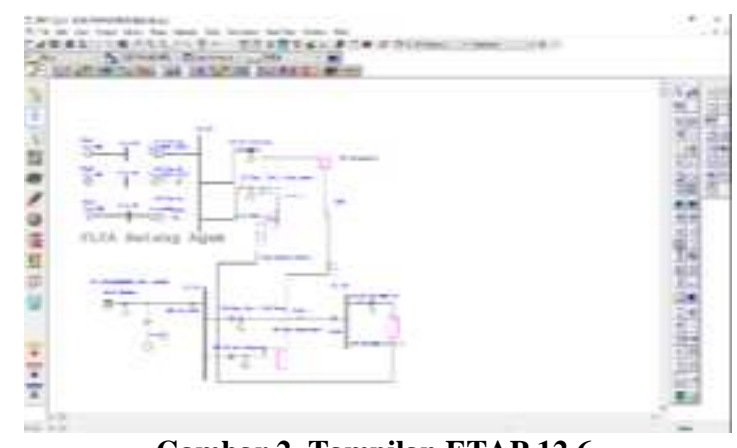

Gambar 2. Tampilan ETAP 12.6

HASIL DAN PEMBAHASAN

Skema Permasalahan Jaringan

PLTA Batang Agam mempunyai 4 feeder keluaran yang merupakan jaringan distribusi $20 \mathrm{kV}$. Dua dari keempat feeder merupakan jalur penghubung PLTA Batang Agam dengan sistem interkoneksi melalui Gardu Induk, yaitu feeder 1 Bukittingi dengan Gardu Induk Kota Bukittinggi dan feeder 3 Payakumbuh 1 dengan Gardu Induk Kota Payakumbuh. Akan tetapi feeder 1 Bukittingi sudah jarang beroperasi dikarenakan faktor gangguan yang lebih banyak, hal ini dapat dibuktikan dengan data penyaluran harian PLTA Batang Agam pada bulan Mei 2021.

Tabel 1. Data Harian Penyaluran 20 kV Bulan Mei 2021 PLTA Batang Agam

\begin{tabular}{|c|c|c|c|c|}
\hline \multirow{2}{*}{$\begin{array}{c}\text { Tang } \\
\text { gal }\end{array}$} & \multicolumn{4}{|c|}{ Penyaluran Daya (KW) } \\
\hline & $\begin{array}{l}\text { Feeder } \\
1\end{array}$ & $\begin{array}{l}\text { Feeder } \\
2\end{array}$ & $\begin{array}{l}\text { Feeder } \\
3\end{array}$ & $\begin{array}{l}\text { Feeder } \\
4\end{array}$ \\
\hline 1 & 0 & 20195 & 179227 & 17909 \\
\hline 2 & 0 & 20438 & 171780 & 18255 \\
\hline 3 & 0 & 20472 & 113723 & 18636 \\
\hline 4 & 0 & 20230 & 92904 & 18186 \\
\hline 5 & 0 & 20403 & 174066 & 18359 \\
\hline 6 & 0 & 20334 & 179955 & 18047 \\
\hline 7 & 0 & 20680 & 116286 & 17008 \\
\hline 8 & 0 & 20507 & 93701 & 18359 \\
\hline 9 & 0 & 20472 & 82270 & 18359 \\
\hline 10 & 0 & 20923 & 168004 & 18602 \\
\hline 11 & 0 & 21234 & 176629 & 19191 \\
\hline
\end{tabular}




\begin{tabular}{|c|c|c|c|c|}
\hline \multirow{2}{*}{$\begin{array}{c}\text { Tang } \\
\text { gal }\end{array}$} & \multicolumn{4}{|c|}{ Penyaluran Daya (KW) } \\
\hline & $\begin{array}{l}\text { Feeder } \\
1\end{array}$ & $\begin{array}{l}\text { Feeder } \\
2\end{array}$ & $\begin{array}{l}\text { Feeder } \\
3\end{array}$ & $\begin{array}{l}\text { Feeder } \\
4\end{array}$ \\
\hline 12 & 0 & 21996 & 153282 & 19883 \\
\hline 13 & 0 & 22031 & 187645 & 20334 \\
\hline 14 & 0 & 21130 & 188788 & 19606 \\
\hline 15 & 0 & 21061 & 186987 & 19294 \\
\hline 16 & 0 & 19017 & 190659 & 18844 \\
\hline 17 & 0 & 21269 & 187714 & 18879 \\
\hline 18 & 0 & 20992 & 189446 & 18498 \\
\hline 19 & 0 & 19745 & 181167 & 18325 \\
\hline 20 & 0 & 21442 & 107668 & 18532 \\
\hline 21 & 0 & 20853 & 102638 & 18879 \\
\hline 22 & 0 & 19953 & 91761 & 17909 \\
\hline 23 & 0 & 20472 & 71774 & 18428 \\
\hline 24 & 32700 & 20611 & 61174 & 18532 \\
\hline 25 & 37099 & 20680 & 59512 & 19398 \\
\hline 26 & 0 & 20091 & 85284 & 18428 \\
\hline 27 & 0 & 19572 & 63253 & 18359 \\
\hline 28 & 0 & 20091 & 60724 & 18325 \\
\hline 29 & 0 & 20022 & 91935 & 17701 \\
\hline 30 & 0 & 19953 & 141920 & 18325 \\
\hline 31 & 0 & 20438 & 104162 & 32042 \\
\hline
\end{tabular}

Melihat permasalahan ini menimbulkan potensi masalah dimana hanya ada satu feeder yang tersisa sebagai penghubung PLTA Batang Agam dengan sistem interkoneksi yaitu feeder 3 Payakumbuh 1. Dengan konfigurasi jaringan yang ada pada saat ini ketika feeder 3 Payakumbuh 1 mengalami gangguan, maka PLTA Batang Agam akan bekerja secara Island Operations sehingga tidak mendapatkan pasokan daya listrik bantuan dari sistem interkoneksi dalam melayani pembebanan Kota Payakumbuh. Hal ini dapat digambarkan dengan skema dibawah ini.

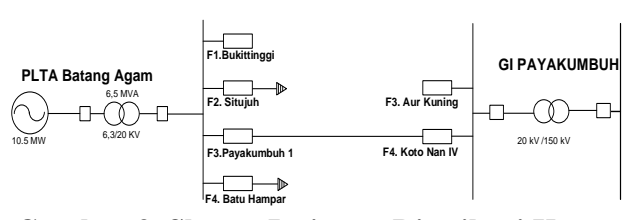

Gambar 3. Skema Jaringan Distribusi Kota Payakumbuh Sebelum Rekonfigurasi

Disamping itu potensi permasalahan ini menyebabkan besar dari nilai susut daya jaringan mengalami peningkatan. Untuk itu, akan dilakukan perencanaan sebuah penarikan jaringan baru sebagai jalur manuver agar
PLTA Batang Agam dapat tetap terhubung dengan sistem interkoneksi sekalipun feeder 3 Payakumbuh 1 mengalami gangguan sehingga dapat menurunkan besar dari nilai susut daya pada jaringan distribusi Kota Payakumbuh.

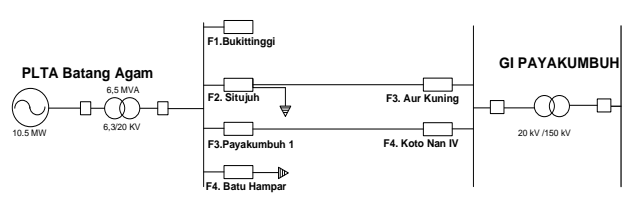

Gambar 4. Skema Jaringan Distribusi Kota Payakumbuh Sesudah Rekonfigurasi.

\section{Analisa Susut Daya menggunakan ETAP 12.6}

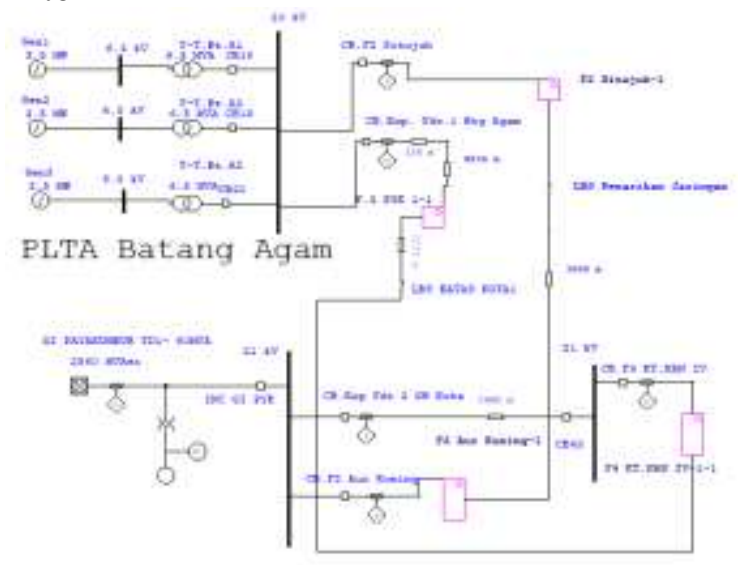

Gambar 5. Permodelan Rangkaian Jaringan Distribusi Kota Paakumbuh

Tabel 2. Susut Daya Sebelum Rekonfigurasi Jaringan

Source (Swing Buses):

\begin{tabular}{c} 
MW \\
\hline-3.241 \\
9.087 \\
5.846 \\
1.346 \\
4.001 \\
0.000 \\
0.000 \\
0.499 \\
0.000
\end{tabular}

Number of Iterations: 3 
Tabel 3. Susut Daya Sesudah Rekonfigurasi Menggunakan Penghantar A3C 70 mm$^{2}$

\begin{tabular}{lc} 
& M w \\
\cline { 2 - 2 } Source (Swing Buses): & -3.552 \\
Source (Non-Swing Buses): & 9.087 \\
Total Demand: & 5.535 \\
Total Motor Load: & 1.314 \\
Total Static Load: & 3.881 \\
Total Constant I Load: & 0.000 \\
Total Generic Load: & 0.000 \\
Apparent Losses: & 0.340 \\
System Mismatch: & 0.000
\end{tabular}

Tabel 4. Susut Daya Sesudah Rekonfigurasi Menggunakan Penghantar A3C 150 mm$^{2}$

\begin{tabular}{lc} 
& MW \\
\cline { 2 - 2 } Source (Swing Buses): & -3.574 \\
Source (Non-Swing Buses): & 9.087 \\
Total Demand: & 5.513 \\
Total Motor Load: & 1.314 \\
Total S tatic Load: & 3.875 \\
Total Constant I Load: & 0.000 \\
Total Generic Load: & 0.000 \\
Apparent Losses: & 0.324 \\
System Mismatch: & 0.000
\end{tabular}

Tabel 5. Susut Daya Sesudah Rekonfigurasi Menggunakan Penghantar A3C 240 mm$^{2}$

\begin{tabular}{lc} 
& \multicolumn{1}{c}{ MW } \\
\cline { 2 - 2 } Source (Swing Buses): & -3.582 \\
Source (Non-Swing Buses): & 9.087 \\
Total Demand: & 5.505 \\
Total Motor Load: & 1.314 \\
Total Static Load: & 3.873 \\
Total Constant I Load: & 0.000 \\
Total Generic Load: & 0.000 \\
Apparent Losses: & 0.319 \\
System Mism atch: &
\end{tabular}

Tabel 6. Nilai susut daya sebelum dan sesudah rekonfigurasi

\begin{tabular}{clc}
\hline No & \multicolumn{1}{c}{ Skema } & $\begin{array}{c}\text { Nilai susut } \\
\text { Daya (MW) }\end{array}$ \\
\hline 1 & $\begin{array}{l}\text { Sebelum } \\
\text { Sesudah dengan A }=70\end{array}$ & 0.499 \\
2 & $\begin{array}{l}\mathrm{mm}^{2} \\
\text { Sesudah dengan A }=150\end{array}$ & 0.34 \\
3 & $\begin{array}{l}\mathrm{mm}^{2} \\
\text { Sesudah dengan A }=240\end{array}$ & 0.324 \\
4 & $\mathrm{~mm}^{2}$ & 0.319 \\
\hline
\end{tabular}

Keterangan: $\mathrm{A}=$ Luas penampang penghantar $\left(\mathrm{mm}^{2}\right)$

\section{NILAI SUSUT DAYA (MW)}

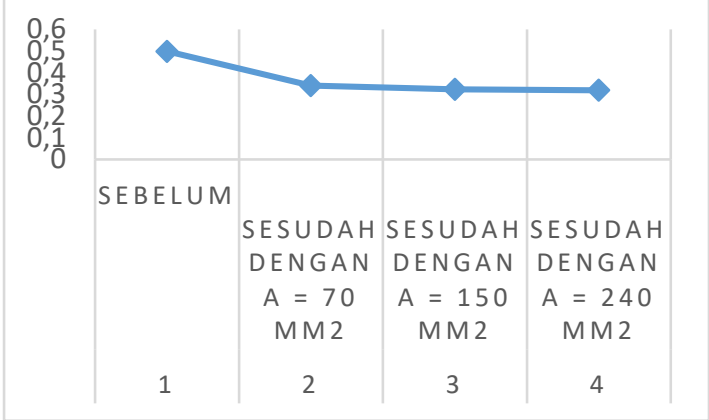

Gambar 6. Grafik Nilai susut daya sebelum dan sesudah rekonfigurasi

Berdasarkan hasil diatas, dapat diketahui bahwa setelah melakukan rekonfigurasi jaringan, nilai susut daya pada jaringan distribusi Kota Payakumbuh mengalami penurunan, Adapun rekonfigurasi menggunakan penghantar dengan luas penampang $240 \mathrm{~mm}^{2}$ mempunyai nilai susut daya yang paling rendah.

Nilai susut daya akan sebanding dengan besar tahanan pada suatu jaringan, semakin besar tahanan maka akan semakin besar nilai susut daya pada jaringan. Untuk itu jika menginginkan nilai tahanan yang lebih kecil pada suatu tahanan ialah dengan cara menambah luas dari penampangnya. Semakin besar luas penampang penghantar yang digunakan maka nilai tahanan penghantar akan semakin kecil, sehingga nilai susut daya juga akan semakin kecil. 


\section{SIMPULAN DAN SARAN}

Berdasarkan dari hasil penelitian dan pembahasan maka penelitian ini dapat disimpulkan sebagai berikut:

1. Penarikan jaringan baru sebagai jalur manuver agar PLTA Batang Agam dapat tetap terhubung dengan sistem interkoneksi sekalipun feeder 3 Payakumbuh 1 mengalami gangguan sehingga dapat menurunkan besar dari nilai susut daya pada jaringan distribusi Kota Payakumbuh.

2. Nilai susut daya sebelum rekonfigurasi jaringan ialah sebesar 0,499 MW. Setelah dilakukan rekonfigurasi jaringan nilai susut daya menurun, dengan menggunakan penghantar $240 \mathrm{~mm}^{2}$

3. Nilai susut daya terkecil diperoleh sebesar 0,319 MW. Kemudian dengan penghantar $150 \mathrm{~mm}^{2}$ nilai susut daya sebesar 0,324 MW, dan dengan penghantar $70 \mathrm{~mm}^{2}$ nilai susut daya sebesar 0,340 MW. Luas penampang penghantar akan berpengaruh signifikan pada nilai susut daya pada jaringan distribusi. Hal tersebut sangat berguna bagi PT.PLN (persero) karena dengan menurunkan nilai susut daya artinya dapat meningkatkan keandalan sistem tenaga listrik.

Adapun saran yang dapat penilis sampaikan adalah, dalam melakukan simulasi menggunakan software ETAP12.6 menggunakan data-data terbaru agar mendekati hasil yang ada dilapangan. Dan dalam memilih luas penampang penghantar yang digunakan sebaiknya juga memperhitungkan dari segi ekonomis.

\section{DAFTAR PUSTAKA}

Abdullah, D., \& Badaruddin, B. (2020). Analisa Perbaikan Penampang Penghantar Guna Mengurangi Drop Tegangan dan Simulasi Etap 16.0 Pada JTR GD KRDB di Wilayah Kerja PT. PLN (Persero) ULP Serang Kota. Jurnal Teknologi Elektro, 11(1), 24. https://doi.org/10.22441/jte.2020.v11i1. 004

Cahyono, A., Hidayat, H. K., Arfaah, S., \& Ali, M. (2017). Rekonfigurasi Jaringan Distribusi Radial Untuk Mengurangi Rugi Daya Pada Penyulang Jatirejo Rayon Mojoagung Menggunakan
Metode Binary Particle Swarm Optimization (BPSO). SAINTEK II2017, UB, Malang, September, 103106.

Jenis-Jenis Kawat Penghantar Pada Saluran Udara Tegangan Menengah (SUTM). (2018). $20 \quad$ Agustus. https://www.duniapembangkitlistrik.co $\mathrm{m} / 2018 / 08 /$ jenis-jenis-kawatpenghantar-pada.html

Khoiriyah, S. (2018). Analisa Susut Daya Dan Energi Pada Jaringan Distribusi Di Gardu Induk Bringin Penyulang BRG-4 Menggunakan Software ETAP 12.6. Computers and Industrial Engineering, 2(January), 6.

Krisnandi, G. O. (2019). Analisis Blackout dan Setting Under Frequency Relay (UFR) terhadap Beban Tinggi Pada PLTU Cirebon Power SuperCritical 660MW.

Maulana, D. A. (n.d.). Analisa Susut Daya Dan Drop Tegangan Terhadap Jaringan Tegangan Menengah 20kv Pada Gardu Induk Pandean Lamper Semarang. Prosiding Konferensi Ilmiah Mahasiswa UNISSULA (KIMU) 2.

Narottama, A. A. N. M., Sunaya, I. G. A. M., Purbhawa, I. M., \& Noviyanti, K. R. D. (2014). Analisis Pengaruh Rekonfigurasi Jaringan Terhadap Pembebanan Transformator pada Gardu Distribusi KA 1316 Penyulang Sriwijaya. 4 No.3.

Prasetijo, H. (2010). Rekonfigurasi Jaringan Distribusi $20 \mathrm{KV}$ Untuk Perbaikan Profil Tegangan Dan Susut Daya Listrik. 11 No. 2.

Pratama, I. Y., \& Budiman, A. (2019). Analisis Rugi Daya Saat Manuver Jaringan Dengan Etap Power Station 12.6.

Putri, N. Y. (2020). Analisis Keandalan Sistem Distribusi 20 KV Dengan Indeks Keandalan SAIDI DAN SAIFI PT.PLN (PERSERO)ULP Kota Bekasi Tahun 2019.

Setiawan, D. N. (2018). Analisis Susut Daya Listrik pada Penyulang $20 \mathrm{kV}$ Gardu Induk Wonogiri.

Yudha, H. M. (1990). Optimasi Konfigurasi Ulang Jaringan Distribusi Dalam Menekan Susut Daya. 